\title{
EXERCISE AND DEPRESSION: A TREATMENT MANUAL
}

\section{I van der Merwe}

D Litt et Phil

Lecturer, Department of Psychology, RAU

Corresponding author: Ivdm@lw.rau.ac.za

\section{S Naudé}

D Litt et Phil

Private practitioner

Keywords: manual-based programme; short-term intervention; cognitive behavioural model; exercise therapy; medication; depression; major depression; dysthymia; individual therapy; Hamilton Depression Rating Scale; Millon Clinical Multi-Axial Inventory II; Nowlis Mood Adjective Checklist

\begin{abstract}
Increased frequencies in unipolar major depression and dysthymia evolve into chronic depression (Gotlib \& Hammen, 1992:11). Depression is reportedly the most common disorder, comprising $75 \%$ of all psychiatric hospitalisations (Gotlib \& Hammen, 1992:17). In the South African context there are few effective manual-based therapy programmes for the treatment of unipolar major depression or dysthymia. This study aimed to develop a manual-based therapy programme for the treatment of unipolar major depression as well as dysthymia, comprising a short-term intervention strategy (a minimum of eight sessions, and a follow-up session) influenced by a cognitive behavioural model focusing on exercise therapy and medication. The control group received non-specific treatment. The research results indicated a shift in different mood constructs for the sample group, as measured by the Nowlis Mood Adjective Checklist. Furthermore, negative emotional states decreased in severity and positive states increased, during and after the intervention. A significant decrease in depression scales was also found, as measured by the Hamilton Depression Rating Scale and the Millon Multi-Axial Inventory II. Furthermore, the personal accounts of the clients were used to gain insight into changing cognitive structures and perspectives, which indicated an increase in concentration, motivation and sense of control.
\end{abstract}

\section{OPSOMMING}

'n Toename in die voorkoms van unipolêre major depressie en distimie kan tot chroniese depressie ontwikkel (Gotlib \& Hammen, 1992:11). Kliniese depressie is die mees algemene versteuring, wat $75 \%$ van alle psigiatriese hospitalisasies insluit (Gotlib \& Hammen, 1992:17). Binne die Suid-Afrikaanse konteks is daar weinig effektiewe handboekgebaseerde terapeutiese programme vir die behandeling van unipolêre major depressie of distimie. Hierdie studie het gepoog om ' $n$ handboek-gebaseerde terapeutiese program vir die behandeling van unipolêre major depressie asook distimie te ontwikkel, bestaande uit ' $n$ korttermyn intervensiestrategie ('n minimum van agt sessies, en ' $n$ opvolgsessie) vanuit ' $n$ kognitiewe gedragsmodel in samehang met 'n oefeningskomponent en medikasie. Die kontrolegroep was onderworpe aan nie-spesifieke behandeling. Die navorsingsresultate was ' $n$ aanduiding van verandering in verskillende gemoedskonstrukte in die steekproefgroep, soos gemeet deur die Nowlis Gemoedstemmingsvraelys. Verder het negatiewe emosionele toestande in ernstigheidsgraad afgeneem en positiewe toestande het gedurende en na intervensie toegeneem. 'n Beduidende afname in depressieskale het ook plaasgevind, soos gemeet deur die Hamilton Depressie beoordelingskaal, asook Millon se Multi-As Inventaris II. Daar is ook van die persoonlike verslae van kliënte gebruik gemaak om insig te verkry in die verandering van kognitiewe strukture en perspektiewe wat op verhoogde konsentrasie, motivering en sin van kontrole aangedui het. 


\section{INTRODUCTION}

Depression is a common experience, because emotions such as intense sadness, heartache, worry and guilt are inherent in all persons. Williams (1992:34) suggests that everyone becomes a little depressed at times, but sometimes, the depth of a person's depression can outweigh the ability to cope. When individuals become severely depressed they usually feel trapped, which may exacerbate feelings of fear and helplessness. This, in turn, has a debilitating effect, as the sufferer's functioning within the domains of family, occupation and social engagement become impaired. Accordingly, Gotlib and Hammen (1992:58) state that although depression forms part of a universal experience, it is also universally misunderstood.

The presenting symptoms of depression can be debilitating, as they impact on the emotional, cognitive, behavioural, and physiological spheres of functioning (Kaplan \& Sadock, 1998:525). Emotional changes include feelings of sadness (dysphoria), anxiety, anger and aggression. On a cognitive level, changes relate to concentration problems, low self-esteem, negative thought patterns and memory problems (Costello, 1993:120). Behavioural changes relate to feelings of irritability, lethargic behaviour and reduced participation in physical and social activities (Costello, 1993:150). Physically, changes in sleeping and eating patterns occur, as well as the experience of sexual problems, bodily pains and lethargy (Kaplan \& Sadock, 1998:530). The onset of these symptoms may lead to feelings of disempowerment, as well as heighten the crisis experience. Furthermore, this may contribute to socio-economic hardships with regard to the loss of productivity and the cost of treatment (Kaplan \& Sadock, 1998:525).

Gotlib and Hammen (1992:11) suggest that major depression may evolve into chronic depression. Research further reveals that the frequency of depression seems to be increasing (Gotlib \& Hammen, 1992:15; Paykel, 1992:3). Depression has by far become the most common disorder, comprising $75 \%$ of all hospitalisations (Gotlib \& Hammen, 1992:17). Therefore an urgent need exists for an intervention that may relieve, as well as prevent the onset of this psychiatric disorder. Furthermore, the incidence of depression may be more underreported than is generally known, and many depressed individuals might not receive treatment (Scott,
Scott, Tacchi \& Jones, 1994:58). According to Johnson and Miller (1994:226) the greater the time period that elapses without treatment, the greater the chance of the development of chronic depression. The challenge lies not only in the recognition of depression, but also in the administration of effective treatment aimed at relieving the immediate crisis and experience of pain. A short-term crisis intervention directed at relieving the patient's sense of pain and discomfort is often required (McGinn \& Sanderson, 2003:24). It is important to find a solution that can be maintained on a long-term basis, as well as a preventative approach that can aid individuals' capacity to cope with future life crises and transitions.

In South Africa changes in the scientific and health sectors correspond with the changes in the current socio-economic climate. As a result, secondary and tertiary health care is moving towards a more cost-effective model. Due to these changes, current treatments need to become more cost-effective. The ideal would be to treat as many people as possible in a cost-effective manner, with the highest percentage of successful outcomes. In the light of these factors it is important to focus on short-term cost-effective approaches in treating depression.

The past decade focused on cognitive behavioural therapy in the treatment of psychological illnesses (Lange \& Van Woudenberg, 1994:65; Williams, 1992:12). According to Scott et al. (1994:63) short-term cognitive behavioural therapy produces significant results in the treatment of depression. However, despite recent studies indicating the effectiveness of cognitive behavioural therapy in treating depression, an in-depth literature search did not reveal the availability of a manual-orientated programme for the treatment of unipolar major depression and dysthymia in South Africa. The aim of this research was to construct a programme that would adhere to a multi-dimensional paradigm, interfacing the different components identified in previous research. This study aimed at developing a manualbased therapy programme for the treatment of unipolar major depression and dysthymia that would consist of a short-term intervention strategy (a minimum of eight sessions, and a follow-up session) influenced by a cognitive behavioural model focusing on exercise therapy. Both unipolar major depression and dysthymia are characterised by the presence of a depressed mood 
(Kaplan \& Sadock, 1998: 545). The severity and duration of the various symptoms differentiate these mood disorders. Unipolar major depression is defined by the presence of symptoms over a period of at least two weeks, and episodes are separated by a period of at least two months. Dysthymia shares many of the symptoms of unipolar major depression but differs in its course. The symptoms are milder and remain over a period of at least two years.

\section{CONCEPTUALISING THE PROGRAMME: INTERVENING ON DIFFERENT LEVELS}

Conceptualisation of the manual-based programme was influenced by the multi-faceted and complex view of the individual patient. It was assumed that the individual should not be treated solely in a uni-dimensional manner, but rather be understood from a holistic perspective. In an attempt to employ a multi-faceted approach, the intervention was informed by theories associated with cognitive behavioural therapy, exercise therapy, short-term therapy and medication. Furthermore, personality was understood to be an important intercepting factor in the experience of depression. These factors will be discussed in detail.

Cognitive-Behavioural Therapy suggests that an important relationship exists between the cognitive capabilities of a person. It implies that there is a difference between intra-psychological and inter-psychological conflicts (Hauck, 1991:323), and proposes that interplay between cognitions and emotions exist. Beck, 1976 (in Williams, 1992:23) states that the nature of a person's emotional response depends on how the specific event is perceived. The ideal is then to change this perception and in turn influence emotions. This subsequently has a further influence on perception. In altering emotions to become more positive, it is possible for an individual to become more perceptive to changing relative cognitive styles of thinking.

Depressive cognitions can also influence the affective state of the individual, therefore when intervening on a cognitive level, one could change the mood constructs as well as the behaviour (Barlow, 1993:289). Depression can influence the cognitive states of the individual initiating a pathogenic circle, where the individual gravitates toward a centre of darkness (Costello, 1993:102). According to Greenberg (2002:174) feelings (emotions) are greatly intertwined with thinking, and emotion cannot be separated from cognition. It is further acknowledged that the relationship between thinking and feeling is complex in nature. Attending to emotions and becoming aware of them, as well as being able to express them in certain instances, assists in accessing biologically adaptive information that can aid problem solving and facilitate therapeutic change. Williams (1992:89) as well as Kaplan and Sadock (1998:555) mention that significant results are achieved when using cognitive behavioural therapy in treating depression. A recent follow-up study shows that psychotherapy, particularly cognitive behavioural therapy, is as effective as antidepressant medication in the treatment of severely depressed patients (Rabasca, 1999:2). Furthermore Williams (1992:60) demonstrates the advantage of using both cognitive and behavioural aspects. A cognitive behavioural model addresses the person's negative cognitions in a structured manner, within the framework of short-term therapy.

While the impact of cognitive behavioural therapy in the treatment of depression is understood to be vital, the clinical utility of exercise therapy is also explored. Dubbert (2002:526) and Raglin (1997:107) agree that patients with a history of unipolar major depression and dysthymia react positively when using a combination of therapies, specifically exercise prescriptions, traditional biochemical treatment, as well as psychotherapy. Exercise therapy addresses the physiological aspects involved in depression (Yeal \& Lidor, 2003:405). It seems to attend to both the biochemical impact of depression and the behavioural aspects; a mere positive and motivated stride can elicit feelings of empowerment and relief from the entrapment of lethargic behaviour. According to Tkachuk and Martin (1999:276) regular exercise is a cost-effective method of treatment for mild to moderate depression. These results compare favourably to individual and group psychotherapy, as well as cognitive therapy. In a study done by Tkachuk and Martin (1999:281), exercise was found to be an effective shortterm, cost-effective treatment, and useful in a comprehensive treatment programme aimed at preventing more severe episodes of this disorder.

While the cognitive and behavioural factors of depression need to be addressed, the physiology and biology of depression cannot be ignored. Medication has been reported to be a highly effective mode of treatment for 
depression. Medication can facilitate a severely depressed patient in engaging more effectively with the therapeutic process. However, it is essential to ensure that medication is not used in isolation in the treatment of depression. Safran (1998:102) suggests that patients might undermine their psychological coping mechanisms when using medication on a long-term basis. Therefore it becomes important for patients to acquire new skills, as well as to participate in problem resolution as part of their healing process. Colin (2003:19) supports this claim when he posits that the debate around depression and treatment is no longer an either/or debate, but rather a focus on combination therapy.

Therapy provides the opportunity to explore the experience of depression. Short-term therapy is an immediate intervention, which lays claim to a higher level of therapeutic activities, along with the identification of a clear focus within a limited time frame (Barkham, 1993:105). Intervening on an emotional level can influence the incidence of recovery. Greenberg (2002:115) perceives emotional arousal as an important factor in persuasion and healing. An increase in emotion $/ \mathrm{mood}$ creates a sense of empowerment, and motivates the client to respond in a more positive manner towards therapeutic intervention. According to Greenberg (2002:117) clients themselves perceive their emotional experience as an important factor in change. Therapy enables the depressive client to experience an immediate improvement through experiences of hope and motivation elicited by the process, outcome and completion of therapy.

Furthermore, Gollan (2000:3) notes that personality style plays an important role in the mediation of one's emotional experience, and therefore also impacts on the experience of depression. Gollan (2000:5) found that people who demonstrated aggressive behaviour at the end of treatment were more likely to experience recurrent episodes of depression, as were people who experienced lower levels of pleasure. The relation between emotions and the healthy personality is highly probable. The question that arises is: what are the emotive dynamics in the depressive client? Avia (1997:35) notes that positive emotions play an important role in several psychological processes and an overall sense of well-being. One therefore needs to ask how one can intervene, in order to change negative emotions to become more positive. Thus, in designing an intervention strategy the focus should not only be directed at the pathological model of intervention, but also attend to therapy that strives towards achieving a healthier, more resilient individual. Avia (1997:34) supports this view by stating that "...to be in a good mood, to feel optimistic, to feel satisfied, to experience wellbeing...(are) very probably, essential aspects of the healthy personality".

It was hypothesised that a manual-based intervention would enhance the prognosis of the clients' problems. The different levels of treatment in this programme focused on biological, physical, cognitive, behavioural and emotive aspects of functioning. Beck and Young (1984:204) support this view by stating that when attempting to change "....depressive cognitions, we can simultaneously change the characteristic mood, behaviour, and (we presume) biochemistry of depression." The intervention thus aimed at using a multiple level approach in anticipation that this would increase the clients' rate of recovery. Furthermore, it was anticipated that through this multi-factorial approach the clients' levels of resilience would be strengthened. The idea of resilience is based on the study of solutogenesis, which focuses on health rather than pathology (Antonovsky, 1993:725). From this perspective, participants' potential to cope successfully with their situation could be enhanced by therapeutic intervention. It was hypothesised that a multi-factorial approach would bring this ability to the fore.

\section{SAMPLE AND ASSESMENT INSTRU- MENTS}

A sample consisting of 79 outpatients was purposively selected. They had requested therapy or were referred by practitioners and/or psychiatrists. Participants were included in the study on a voluntary basis and with provision of informed consent. The participants met the DSM-IV (American Psychiatric Association, 1994) criteria for major depressive disorder or dysthymia, which was determined by using the Hamilton Depression Rating Scale (HDRS) and the Millon Clinical Multi-Axial Inventory II (MCMI-II) as measures of symptomatology. The minimum score for major depressive disorder, as measured by the HDRS, was 18 , and the minimum score for dysthymia was 14,5 . The minimum scores on the MCMI-II for unipolar major depression were 58,5 
and 48,5 for dysthymia.

\section{The Hamilton Depression Rating Scale (HDRS)}

Although the HDRS cannot be used diagnostically (Kaplan \& Sadock, 1998:560) it provides useful information regarding the intensity of depression. It also offers extensive information regarding the symptoms of depression, including psychomotor symptoms, guilt, loss of energy and sleeping problems. The HDRS consists of 17 depressive symptoms that are marked on a five-point Likert scale, and added up to obtain a total score. A maximum score of 50 can be obtained on the HDRS. A score of 14 indicates that treatment is justified, and a score of seven or less indicates remission. When the HDRS post-test scores decrease by a third or less, patients experience the treatment as having been successful (Williams, 1992:68).

It is indicated that the HDRS has a high degree of scale reliability, interreliability $(0,90)$, as well as concurrent, discriminatory and construct validity (Endicott, Cohen, Nee, Fleiss \& Sarantakos, 1981:100; Potts, Daniels, Burnam \& Wells, 1990:349). The HDRS is very sensitive in detecting changes in the severity of depressive symptomology with the progress of time, and can be used as a measure regarding the effectiveness of therapy (Kaplan \& Sadock, 1998:560).

\section{The Millon Clinical Multi-Axial Inventory II (MCMI-II)}

The MCMI-II is a clinical measuring instrument, and is used in conjunction with the DSM-IV. This inventory is a pencil and paper test consisting of 175 true or false items. The MCMI-II has 22 clinical scales, which are divided into three groups, namely the Personality Style Scale, the Personality Pathology Scale and the Clinical Syndrome Scale.

The reliability with regard to the correlation coefficient is $0,80-0,89$ for the personality scales, $0,79-0,89$ for the personality pathology scales, and 0,79 $-0,91$ for the syndrome scales. Cross validation data support the generalisability, reliability and accuracy of the diagnostic scale cut-off points and interpretations of profiles of the MCMI-II (Millon, 1987, 1997). Cut-off points used in this study were 24 (25) for severe depression (seen in hospitalised patients), a score greater than 17 for mild depression (seen in outpatients), and a score less than six in the absence of depression (or in remission).

\section{The Nowlis Mood Adjective Checklist (NMAC)}

The NMAC serves as an incentive for the confirmation of mood, and is designed to measure mood changes. The reliability associated with measures of change is dependent on the reliability of the scores of mood at a specific time (Tomkins \& Izard, 1966:24).

The NMAC is also a pencil and paper questionnaire, which was administered after each therapy session, in order to monitor each patient's mood from one session to the next. The NMAC consists of 33 items and 11 factors. As a result of the empirical relations and the ease with which the test is administered, the NMAC in its current form is a useful instrument in monitoring affect, emotion, and mood, as well as stress responses.

The participants were randomly divided into an experimental and control group. The experimental group was subjected to a short-term cognitive behavioural manualbased intervention, consisting of eight therapy sessions with the aim of decreasing the intensity and occurrence of unipolar major depression, as well as dysthymia. The average age of the major depressive patients was 37,8 years for the experimental group and 46 years for the control group. The average age of the experimental group of dysthymic patients was 38 years and 44 years for the control group. According to the DSM-IV (American Psychiatric Association, 1994) both the dysthymic and major depressive groups of patients were severely depressed and seemed to experience an acute phase of depression. Participants were ensured of their anonymity, as well as of the confidentiality regarding information associated with their treatment.

\section{METHOD}

\section{Development of the treatment manual}

The treatment programme was based on a cognitive behavioural model of therapy. The focus was on shortterm therapy and general life-skills training, which included communication, decision-making, problem solving, stress management, relaxation and thinking skills. 
Physical exercise was also included, and formed the fourth element of this manual-based programme. These aspects produced an integral part of the treatment. Although medication was not the primary focus of this treatment programme, it was viewed as important, especially when patients suffered from acute depression. Information provided to participants regarding the use of medication and its side-effects was also included in this programme.

This study utilised a paradigm that includes some of the notions of "precipitation theory" of cognition and mood, as discussed by Williams (1992:60). It also incorporated the vulnerability theory as postulated by Beck, 1967 (in Williams, 1992:23). Cognitive components were studied by using Beck's cognitive theory of depression (Williams, 1992:23). The different components of the theory were targeted in therapy, namely negative automatic thoughts, systematic logical errors and depressogenic schemas (factors that contribute or are related to depression) according to Williams (1992:63). In addition, the emotive factors relating to cognitive behavioural therapy were targeted within therapy. The relation and interconnectedness between feelings, cognitions and behaviour were highlighted. It was anticipated that mood-shifts would occur subsequent to therapeutic interventions.

The synergy of these different aspects of therapy made it possible to treat unipolar major depression, as well as dysthymia. The treatment programme consisted of eight therapy sessions, lasting 60 minutes each, once a week. According to research conducted by Scott et al. (1994:63) patients require more than 20 minutes per session, and seem to benefit from more than six sessions. Correspondingly, within this research the patients indicated that they preferred eight to ten sessions.

\section{Hypothesis}

The following hypothesis was formulated for this study: There will be a significant difference in the indexes of depression, as well as personality between the experimental group in the presence of the manual-based therapy, and the control group in the absence of the manual-based therapy, as an indication of the relative chronicity of the clinical syndrome as measured by the MCMI-II and HDRS.

\section{PROCEDURE}

\section{Statistical Analysis}

This study utilised a pre-post-test experimental design that included the use of a control group. Inferential statistical analysis was used in the form of a t-test for dependent and independent groups. The sample size was limited to time and availability factors.

Each participant was assessed by a psychiatrist and a general practitioner, as well as a psychologist prior to commencing with treatment. The researcher designed the intake interview, which included information regarding the subjects' developmental and psychiatric history, social functioning, and neurological and medical information.

The treatment took place in a church office that was provided for the purpose of this study. Two psychologists in private practice conducted the sessions. One therapist was assigned to the subjects with dysthymic disorder and the other worked with the subjects with major depressive disorder. Each participant was assessed on the HDRS and MCMI-II prior to the first therapy session, as well as after termination of the treatment. The NMAC was administered after each therapy session. The MCMI-Il was used to distinguish between the two categories of depression, namely major depression and dysthymia. The HDRS was used to determine the level of intensity of the affective disorders. The level of intensity ranged from severe to acute levels of depression prior to the administration of the treatment. In addition, each participant was provided with feedback by the researcher regarding his or her progress after the treatment programme.

Subjects were randomly allocated to either the experimental group or the control group. Although both the experimental and control groups received medication, the control group did not receive the same type of therapy techniques as the experimental group, namely a manual-based therapy inclusive of cognitive behaviour and exercise therapy. Due to ethical reasons, the control group was not excluded from receiving therapy as part of their treatment. However, to maintain the requirements of an experiment, the control group was administered a different type of therapy compared to that of the experimental group. Participants in the control group 
received, for example Gestalt therapy, interpersonal therapy, reality therapy and/or narrative therapy. The experimental group was provided with individual therapeutic counselling that formed part of an eight-week treatment programme. A telephonic follow-up investigation, directed at both groups, was conducted four to six weeks following termination of the treatment.

\section{RESULTS}

The t-test was significant with regard to the pre- and post-test scores of the experimental group for major depression and dysthymia ( $p=<0,001$; see Tables 1 and 2) as measured by the HDRS. Results indicate that the experimental group improved significantly from pre- to post-test in the presence of the intervention.
A significant difference was found for the experimental group from pre- to post-test between the independent variables regarding major depression, as measured by the MCMI-II ( $p=<0,01$; see Table 3 ). A highly significant difference ( $p=<0,001$; see Table 3 ) was found on the post-test scores between the experimental and control groups regarding major depression. A highly significant difference $(p=<0,001$; see Table 4) between the independent variables regarding dysthymia was found between the pre- and post-test scores of the experimental group. A highly significant difference $(p=$ $<0,001$; see Table 4) was found on the post-test scores between the experimental and control groups regarding dysthymia.

Table 1: Significance of differences between independent variables regarding unipolar major Depression as measured by the Hamilton Depression Rating Scale

\begin{tabular}{||l|l|l|l|l||}
\hline \hline Groups & $\mathrm{x}$ & $\mathrm{t}$-value & $\mathrm{df}$ & $\mathrm{p}$ \\
\hline Experimental group: & 27,19 & 10,28 & 30 & $<0,001$ \\
Pre-test: & 7,63 & & & \\
Post-test: & 30,94 & $-0,20$ & 34 & $>0,05$ \\
\hline Control group: & 31,39 & & & \\
\hline Pre-test: & & $-1,86$ & 32 & $>0,05$ \\
Post-test: & 27,19 & & & \\
\hline Pre-test: & 30,94 & & & \\
\hline Experimental group: & 7,63 & $-10,78$ & 32 & $<0,001$ \\
Control group: & 31,39 & & & \\
\hline Post-test: & & & \\
Experimental group: & & &
\end{tabular}

Table 2: Significance of differences between independent variables regarding dysthymic depression as measured by the Hamilton Depression Rating Scale

\begin{tabular}{||l|l|l|l|l||}
\hline \hline Groups & $\mathrm{x}$ & $\mathrm{t}-\mathrm{value}$ & $\mathrm{df}$ & $\mathrm{p}$ \\
\hline Experimental group: & 26,73 & 13,49 & 44 & $<0,001$ \\
\hline Pre-test: & 6,95 & & & \\
Post-test: & 29,31 & $-0,06$ & 42 & $>0,05$ \\
\hline Control group: & 29,45 & & & \\
\hline Pre-test: & 26,73 & $-1,41$ & 43 & $>0,05$ \\
Post-test: & 29,31 & & & \\
\hline Pre-test: & & $-11,76$ & 43 & $<0,001$ \\
\hline Experimental group: & 6,95 & & & \\
Control group: & 29,45 & & & \\
\hline Post-test: & & & & \\
Experimental group: & & & & \\
Control group: &
\end{tabular}


Table 3: Significance of differences between independent variables regarding unipolar major depression as measured by the Millon Clinical Multi-Axial Inventory II

\begin{tabular}{||l|l|l|l|l||}
\hline \hline Groups & $\mathrm{x}$ & $\mathrm{t}$-value & $\mathrm{df}$ & $\mathrm{p}$ \\
\hline Experimental group: & 77,81 & 3,55 & 30 & $<0,01$ \\
Pre-test: & 53,37 & & & \\
Post-test: & 89,17 & 0,51 & 34 & $>0,05$ \\
\hline Control group: & 85,11 & & & \\
Pre-test: & 77,81 & $-1,64$ & 32 & $>0,05$ \\
Post-test: & 89,17 & & & \\
\hline Pre-test: & 53,37 & $-4,09$ & 32 & $<0,001$ \\
\hline Experimental group: & 85,11 & & & \\
Control group: & & & \\
\hline Post-test: & & &
\end{tabular}

Table 4: Significance of differences between independent variables regarding dysthymic depression as measured by the Millon Clinical Multi-Axial Inventory II

\begin{tabular}{|c|c|c|c|c|}
\hline Groups & $\bar{x}$ & t-value & deff & $\bar{p}$ \\
\hline $\begin{array}{l}\text { Experimental group } \\
\text { Pre-test: } \\
\text { Post-test: }\end{array}$ & $\begin{array}{l}88,65 \\
54,87\end{array}$ & 4,63 & 44 & $<0,001$ \\
\hline $\begin{array}{l}\text { Control group } \\
\text { Pre-test: } \\
\text { Post-test: }\end{array}$ & $\begin{array}{l}92,27 \\
91,32\end{array}$ & 0,13 & 42 & $>0,05$ \\
\hline $\begin{array}{l}\text { Pre-test: } \\
\text { Experimental group: } \\
\text { Control group: }\end{array}$ & $\begin{array}{l}88,65 \\
92,27\end{array}$ & $-0,69$ & 43 & $>0,05$ \\
\hline $\begin{array}{l}\text { Post-test: } \\
\text { Experimental group: } \\
\text { Control group: }\end{array}$ & $\begin{array}{l}54,87 \\
91,32\end{array}$ & $-4,13$ & 43 & $<0,001$ \\
\hline
\end{tabular}

\section{Descriptive Analysis}

Descriptive analysis was used to determine the effectiveness of each therapy session as indicated by the change of mood during the eight therapy sessions of the manual-based programme. A Time Series Analysis was done to determine session-by-session changes in mood. A time-series graph indicates these changes whereby the abscissa represents the passage of time (therapy sessions). The most significant sessions are indicated in the figures. This was measured using the NMAC. Although all 11 factors were influenced by the therapy, the following factors were regarded as being most important in the treatment of depression: anxiety, fatigue, aggression, vigour and social affection. onset of therapy, but decreased during therapy and stabilised or reached their optimum level of functioning at the end of treatment. Vigour and social affection measured significantly low at the onset of therapy, but measured significantly high after the eight therapy sessions. Vigour correlated with the sharp decrease in fatigue, and also showed an increase during the therapy sessions. There was a general decline in anxiety, fatigue and aggression. 


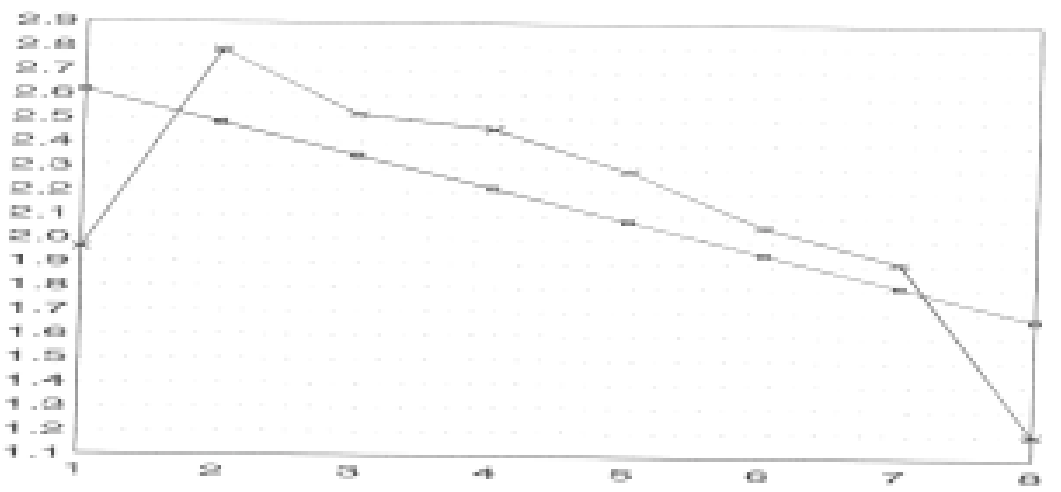

\section{SESSIONS}

${ }^{*}$ Aggression as measured in the experimental group

- Tendency

In general a downward vector has been measured regarding Aggression.

Figure 1: Time series graph - Aggression

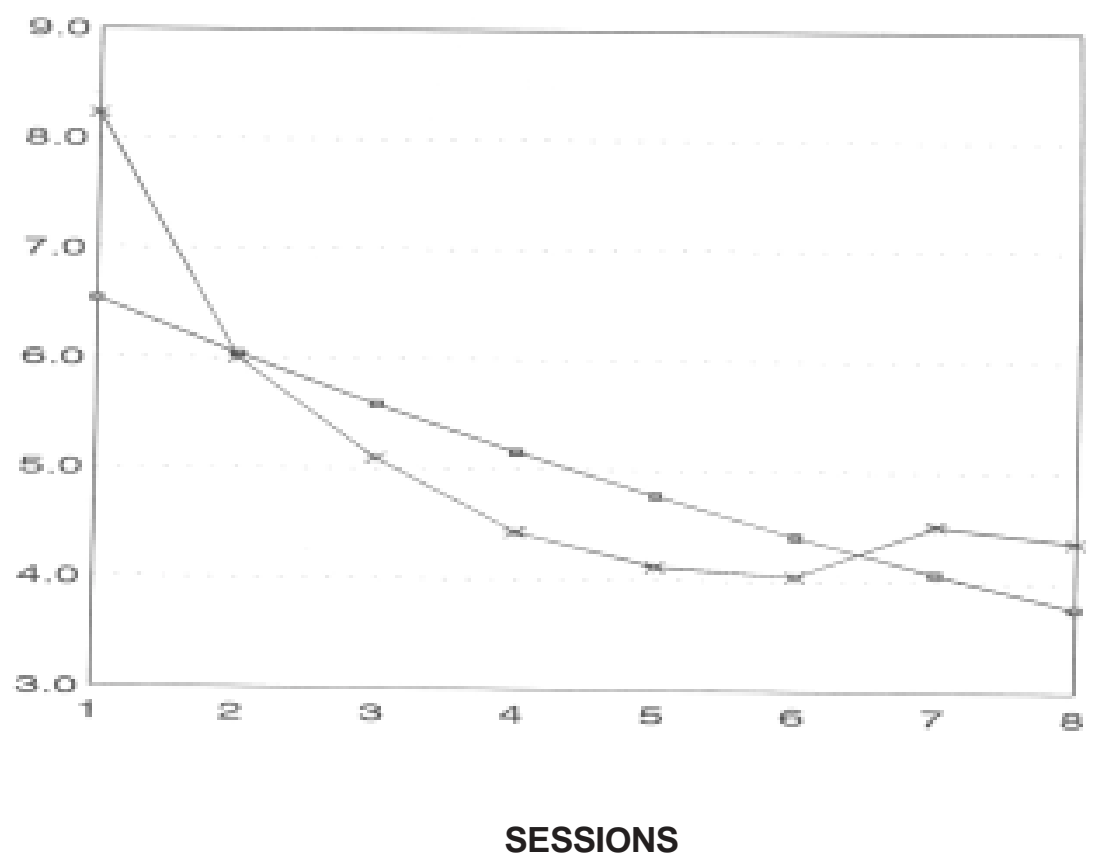

*Anxiety as measured in the experimental group

- Tendency

In general a downward vector has been measured regarding Anxiety.

Figure 2: Time series graph - Anxiety 


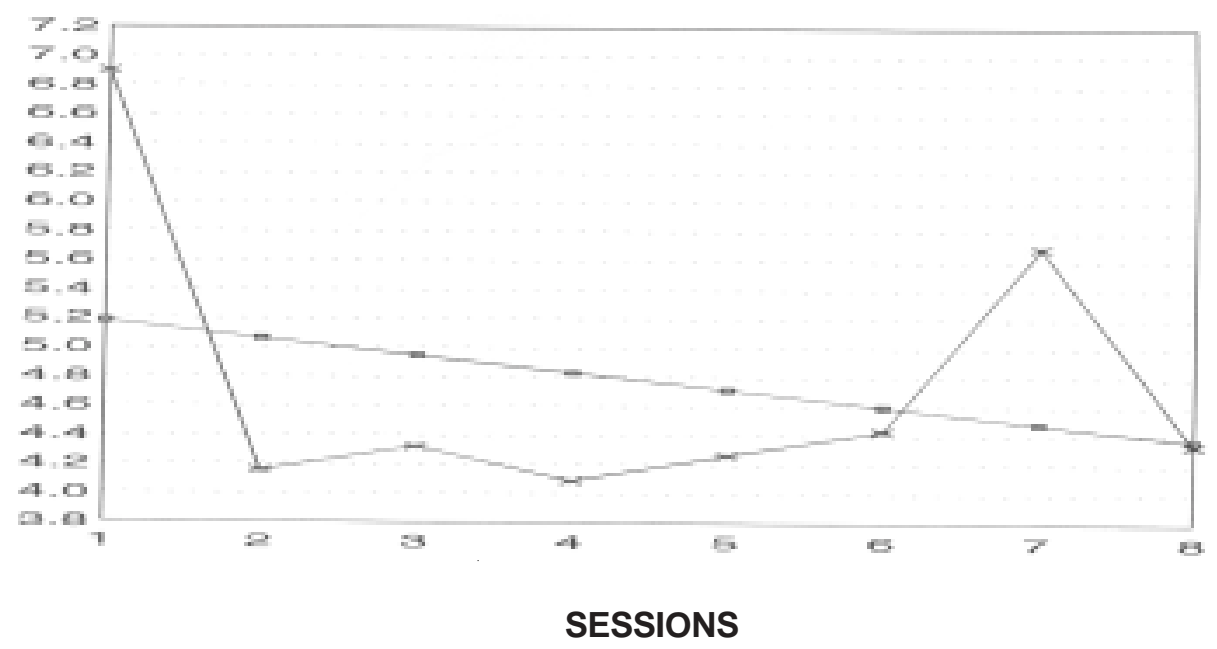

${ }^{*}$ Fatigue as measured in the experimental group

- Tendency

In general a downward vector has been measured regarding Fatigue.

Figure 3: Time graph: Fatigue

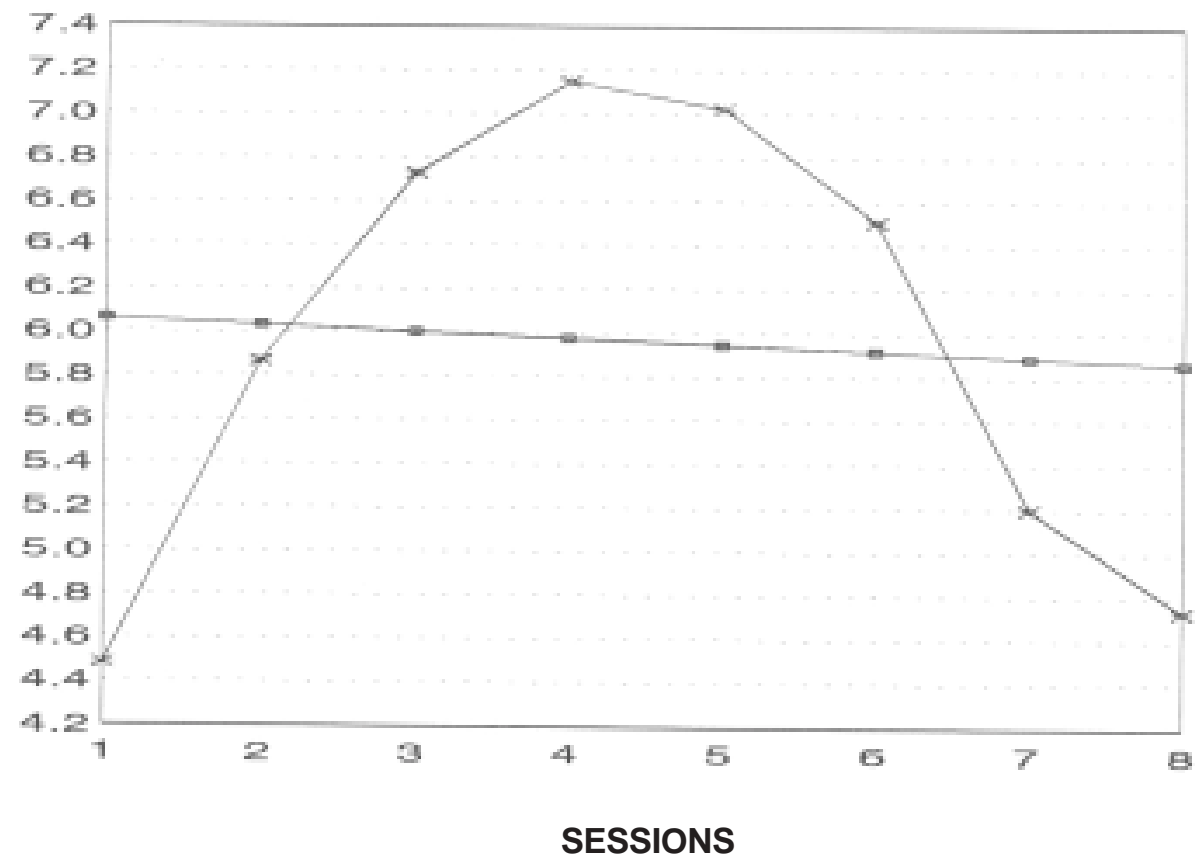

* Social Affect as measured in the experimental group

- Tendency

In general an upward vector was noted in Social Affect.

Figure 4: Time graph - Social Affect 


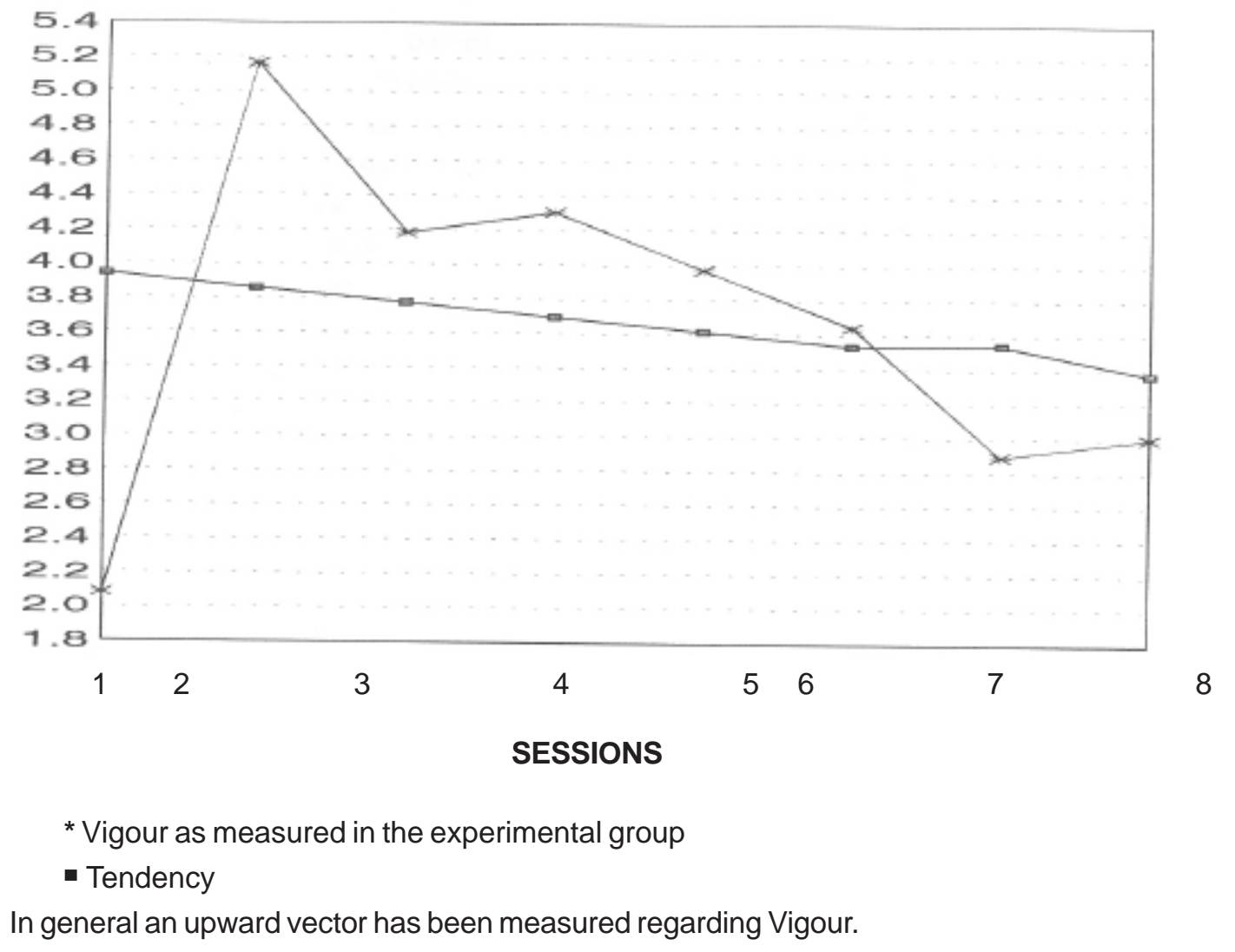

Figure 5: Time graph - Vigour

\section{DISCUSSION}

The results of this study indicate a decrease in the intensity and prevalence of unipolar major depression and dysthymia in the presence of the manual-based intervention. Results indicate that the manual-based programme, which includes cognitive behavioural therapy in conjunction with exercise therapy and medication, is successful in improving depressive symptomology. In certain instances depression decreased to such an extent that an absence of symptoms was reported. The control group, who received a different type of therapy, did not report a decrease in the intensity of the depressive symptoms. These results seem to indicate that other types of therapies might be less effective in treating depression. A possible explanation for this outcome might be associated with therapist-input and personal style.

The MCMI-II not only reported a decrease in the Depression scales, but also indicated changes in the Clinical Personality Pattern, the Personality Pathology, the
Clinical Syndrome, and the Severe Syndrome categories. In the Clinical Personality Pattern category a decrease was found on the Schizoid, Avoidant, and SelfDefeating Scales. In the Personality Pathology category a decrease was indicated on the Schizotypal Scale. In the Clinical Syndrome category a decrease was demonstrated on the Anxiety and Somatoform Scales. A decrease was found in the Severe Syndrome categories regarding the Thought Disorder Scale. With regard to this scale an incidence of $69 \%$ was measured prior to the intervention, whereas an incidence of $48 \%$ was measured at post-test. Although an average of $69 \%$ is not very high, should depression increase to a psychotic state, increased thought disorders might occur (Millon, 1987, 1997).

The decrease in these scales could be a result of the different components of the intervention programme, which addressed some of the problem areas usually found in the above-mentioned personality indexes. These include, for example, poor interpersonal and communication skills, low self-esteem, a negative frame 
of reference, poor stress management, tension and anxiety. The change of mood, as measured by the NMAC, during the eight therapy sessions, provided important information regarding the effect of the intervention programme. Yeal and Lidor (2003:405) define mood as the sum of a person, which resembles a vast diversity of behaviour and experiences. This can also make it possible to use a large amount of responses to study mood, for example, expressive body movements, as well as different aspects of language and fluctuations in self-efficacy. The factors that showed a significant change in mood included aggression, anxiety, fatigue, social affection, and vigour. These changes might be associated with the fact that the participants learnt to express their anger, and cope with aggression in a more constructive solution-focused way. The therapy environment provided a safe haven where the patients could practise new skills without fear of retribution. The patients became less isolated, and depressive behaviour decreased enabling the patients to handle socially taxing situations with more confidence. Exercise therapy and relaxation techniques also contributed to better management of stress and elevation of energy levels, as well as psychomotor functioning. The information regarding the aetiology of depression and its course, as well as the use of medication and its side-effects, may also have contributed to a decrease in anxiety.

The results obtained in this study concur with findings of Lange and Van Woudenberg (1994:73), Ludgate (1994:10), Scott et al. (1994:64) and Yeal and Lidor (2003:405). It should be noted that, although this intervention programme yielded significant results concerning the decrease in depressive symptoms, the patients were informed that a relapse might occur. In order to prepare for such a relapse, telephonic follow-up interviews were made after a period of four to six weeks. The researcher focused on establishing whether initial symptoms had recurred. The follow-ups revealed an absence of relapse, as well as demonstrated that patients experienced a "normal" level of functioning. Participants were informed that the therapist would be available to them, should they require further assistance. Some of the patients made use of this offer, which might indicate that a further session would be advantageous in future programme implementation. This, however, might depend on the individual nature of participants when dealing with crises and recovery. The context of each individual and his/her idiosyncratic characteris- tics should be taken into account. This study also revealed the success of initially dealing with clients on a behavioural level, and then proceeding to a cognitive level in therapy. This appears to support research findings (Watts, 1993:50; Williams, 1992:87) and the DSMIV criteria (American Psychiatric Association, 1994) claiming that depressive patients have problems in effectively utilising their thinking skills. Patients often reported that they felt "fuzzy" and seemed unable to recall information as effectively as prior to the onset of their depression. Participants reported that exercise provided them with increased motivation and ability to concentrate. According to the exercise diaries, exercise therapy seemed to demonstrate an elevation in mood during and after the exercise. This activity "cleared their minds" and could be used as a coping resource in times of anxiety and stressful events. Clients also reported that it gave them a sense of control (the locus of control shifts). In her book regarding exercise, Hays (1999:23) points out that exercise is just as valuable to the psyche as it is to the mind and body. She states that it alleviates stress, and improves clarity and selfesteem. She also supports the notion that exercise should be assigned as "homework" or as a medium of therapy itself. Her viewpoint coincides with those of Bricklin and Spilner (1992:56), as well as Lewis, Sperry and Carlson (1993:126) and Martinson and Morgan (1997:98) that low impact exercise can have a positive effect on depression. It can also be seen as a form of "anti-depressant" that influences mood. Exercise also has a calming effect on anxious patients. This could be correlated with the decrease of anxiety as measured by the NMAC. A possible explanation for this mood shift could be related to the release of endorphins in the brain (Bricklin \& Spilner, 1992:58). Although this view is postulated, there is thus far little evidence for this theory. There is, however, research that points to the less familiar neuromodulator, namely norepinephrine, which aids the brain in dealing with the experience of stress (American Psychiatric Association, 1994). The locus coeruleus produces $50 \%$ of the brain's norepinephrine, and connects most of the brain's regions involved with emotional and stress responses (Kaplan \& Sadock, 1998:524). However, higher levels of norepinephrine may not offer a simple solution. According to Bricklin and Spilner (1992:56) exercise enhances the body's ability to respond to stress, and adjusts the responsiveness of the system, making it more efficient, which in turn thwarts depression and 
anxiety. Martinson and Morgan (1997:102) view exercise as a wonder potion, which could even be placed alongside morphine and tricyclic medication in treating depression.

\section{Limitations and recommendations}

This study was done with a small sample group within a specific contextual situation. Therefore these findings cannot be generalised to other individuals experiencing depression, and further research with larger and more representative samples is advised. Therapist input and personal style might also have played an important role in this study and could be viewed as potential extraneous variables. It is also advisable to attempt a qualitative study regarding the impact of each strategy utilised within this programme. It would be valuable to establish which type of therapy is most effective and prevalent in the treatment of depression. This could help to refine the programme and increase its effectiveness. Furthermore, it was noted that positive emotions and well-being seem to be neglected in the field of research. When one considers this effect on overall functioning, it seems that a link to resilience needs more attention in future research.

\section{LIST OF REFERENCES}

AMERICAN PSYCHIATRIC ASSOCIATION 1994: Diagnostic and statistical manual of mental disorders; fourth edition. Washington: APA.

ANTONOVSKY, A 1993: The structure and properties of the sense of coherence scale. Social Science and Practice, 36(6):725738.

AVIA, MD 1997: Personality and positive emotions. European Journal of Personality, 1(11):33-56.

BARKHAM, M 1993: Counselling for a brief period. (In: Dryden, W ed. 1993: Questions and answers in counselling in action. London: Sage, pp 97-128.)

BARLOW, DH 1993: Clinical handbook of psychological disorders. New York: Guilford.

BECK, AT \& YOUNG, JE 1984: Depression. (In: Barlow, DH ed. 1984: Clinical handbook of psychological disorders: A step-bystep treatment manual. New York: Guilford, pp 184-232.)

BRICKLIN, M \& SPILNER, M 1992: Prevention's practical encyclopaedia of walking for health. Pennsylvania: Rodale.

COLIN, C 2003: Combining pharmacotherapy and psychotherapy: The example of depressive disorders. South African Psychiatry Review, May:19-22.
COSTELLO, CG 1993: Symptoms of depression. New York: Wiley. DUBBERT, PM 2002. Physical activity and exercise: recent advances and current challenges. Journal of Consulting and Clinical Psychology, 70:526.

ENDICOTT, J; COHEN, J; NEE, J; FLEISS, J \& SARANTAKOS, S 1981: Hamilton Depression Rating Scale. Archives of General Psychiatry, 38:98-103.

GOLLAN, J 2000: Personality styles may predict susceptibility to depression. Monitor on Psychology, 31:2-12.

GOTLIB, IH \& HAMMEN, CL 1992: Psychological aspects of depression: Toward a cognitive interpersonal integration. New York: Wiley.

GREENBERG, LS 2002. Emotion-focused therapy: Coaching clients to work through their feelings. Washington DC: APA.

HAUCK, PA 1991: RET and the assertive process. (In: Bernard, E ed. 1991: Using rational emotive therapy effectively. New York: Plenum, pp 319-340.)

HAYS, KF 1999: Walking it out: Using exercise in psychotherapy. New York: APA.

JOHNSON, LD \& MILLER, SD 1994: Modification of depression risk factors: A solution-focused approach. Psychotherapy, 31(2):224250.

KAPLAN, HI \& SADOCK, BJ 1998: Synopsis of psychiatry: Behavioural sciences, clinical psychiatry. Baltimore: Williams \& Wilkins.

LANGE, A \& VAN WOUDENBERG, J 1994: Cognitive restructuring in behaviour therapy and in psychoanalytical therapy: A content analysis of therapy sessions. Behavioural and Cognitive Psychotherapy, 22:65-73.

LEWIS, JA; SPERRY, L \& CARLSON, J 1993: Health counseling. California: Brooks/Cole.

LUDGATE, JW 1994: Cognitive behaviour therapy and depressive relapse: Justified optimism or unwarranted complacency? Behavioural and Cognitive Psychotherapy, 22:1-11. MARTINSON, EW \& MORGAN, WR 1997: Antidepressant effects of physical activity. (In: Morgan, WF ed. 1997: Physical activity and mental health. Washington DC: Taylor \& Francis, pp 93-106.) MCGINN, LK \& SANDERSON, CW 2003: What allows CBT to be brief: Overview, efficacy and crucial factors facilitating brief treatment. Clinical Psychology: Science and Practice, 8 (1):2329.

MILLON, T 1987: Millon Clinical Multiaxial Inventory II. Minneapolis: National Computer Systems.

MILLON, T 1997: The Millon Inventories: Clinical and personality assessment. New York: Guilford.

PAYKEL, ES 1992: Handbook of affective disorders. Edinburgh: Churchill Livingstone.

POTTS, MK; DANIELS, M; BURNAM, AM \& WELLS, KB 1990: A structured interview version of the Hamilton Depression Rating 
Scale: Evidence reliability and versatility of administration. Journal of Psychiatric Research, 24(4):335-350.

RABASCA, L 1999: Psychotherapy may be as useful as drugs in treating depression, study suggests. APA Monitor, 30(8):1-2. RAGLIN, RH 1997: Anxiolytic effects of physical activity. (In: Morgon, WP ed. 1997: Physical activity and mental health. Washington DC: Taylor \& Francis, pp 107-126.)

SAFRAN, JD 1998: Widening the scope of cognitive therapy: The therapeutic relationship, emotion, and the process of change. Northvale, New York: J Aronson.

SCOTT, CS; SCOTT, JL; TACCHI, MJ \& JONES, RH 1994: Abbreviated cognitive therapy for depression: A pilot study in primary care. Behavioral Cognitive Psychotherapy, 22:57-64.

TKACHUK, GA \& MARTIN, GL 1999: Exercise therapy for patients with psychiatric disorders: Research and clinical implications. Professional Psychology: Research and practice, 30(3):275282.

TOMKINS, SS \& IZARD, CE 1966: Affect, cognition, and personality: Empirical studies. London: Tavistock.

WATTS, FN 1993: Problems of memory and concentration. (In: Costello CG ed. 1993: Symptoms of depression. New York: Wiley, pp 31-55.)

WILLIAMS, JMG 1992: The psychosocial treatment of depression: A guide to the theory and practice of cognitive behaviour therapy. London: Routledge.

YEAL, N \& LIDOR, R 2003: Mood alterations in mindful versus aerobic exercise modes. Journal of Psychology, 137(5):405. 